\title{
Study of application of intelligent agents in e-learning systems
}

\author{
Zohre FASIHFAR $^{1, *}$, Hamidreza ROKHSATI ${ }^{2}$ \\ ${ }^{1}$ Faculty member, Faculty of Electrical and Computer Engineering, Hakim Sabzevari University \\ ${ }^{2}$ B.S. student in Computer Engineering, Faculty of Electrical and Computer Engineering, Hakim \\ Sabzevari University
}

\begin{abstract}
In this paper, the advantages of using intelligent agents were investigated in order to facilitate and customize suitable electronic learning resources and reinforce collaboration in e-learning environment. Using intelligent agent, learning is personalized based on person's prior knowledge. E-learning agents monitor electronic learning environment and improve learning and collaboration which is based on learners' prior knowledge, social features and learning styles. E-learning agents should easily admit of exploration of new learning objects, allowing learners to customize materials presented so that learning and collaboration results can improve in an e-learning environment; it is a learning agent that should offer tangible benefits to organization if operated in online learning or learning environments.
\end{abstract}

Keywords: E-learning, Intelligent agents, Environment, Learning.

\section{Introduction}

E-learning is commercially economical and easily accessible to all individuals from every stratum and position. One of the points that received the attention of many people regarding this method of education is the freedom to choose topics and headings that interest people. In this method, no one has a clear and specific limit for learning, as he can easily get access to contents of all scientific disciplines in the shortest time possible. In this method, knowledge and experiences are made available through multimedia tools, in that individuals can take advantage of this learning effectively and without attending the classroom. The seven elements constitute the main features of e-learning; 1. Separation of teacher and learner, 2. A systematic educational organization for supporting self-learning without border and time, 3. Opportunity for learning everywhere and anytime for all people, 4. Use of technical and specialized media for alliance between instructor and students as well as learning concepts and experiences. 5. A bilateral communicative system, 6. Face-to-face and periodical sessions for educational and social purposes, 7. Admission of an industrialized format for learning with a focus on mass production and high quality regarding learning tools so that all students can benefit from the self-learning tool at the same and quality. 


\section{Agent}

It is something which is able to understand its surrounding area through sensors and effect on the environment via effectors. Human agent has organs like ears, eyes, and other organs in order to sense, as he has limb, nose and other organs in order to exert an effect. Robotic agents have replaced cameras and infrared detectors with sensors and various motors with effectors. Software agents have coded nasal strings as perceivers of environment and action.

\section{Intelligent agent}

In the context of artificial intelligence, intelligent agent is referred to as an autonomous entity which identifies its surroundings in an environment and does some actions in this environment and all that it does are in line with achieving its goals. The systems have the chance to learn and use its acquired knowledge in order to fulfil their goals. The agents may be either so simple or complicated.

\section{Operators' performance}

Logical agent is something that does something right.

\section{Efficiency benchmark}

The term is used for how to do something; a benchmark that determined how and when an agent reaches an objective. Then there is no single criterion for all intelligent agents.

\section{Meta knowledge}

Omniscient agent who knows all sciences and is owner of a wisdom greater than what a special expert owns knows the meaning of real output of its actions and acts upon it, though meta knowledge is impossible in practice.

\section{Autonomy}

While agents' actions are totally based on inner knowledge, in that it pays no attention to its understanding of external operating environment, the agent lacks autonomy. Autonomous intelligent agent should be able to reach an objective in a wide range of environment, as it should be given sufficient time to adapt itself.

\section{Types of environments}

\subsection{Visible and invisible}

If actor has an access to the entire environment and is able to feel it, the environment is visible, or else it is invisible or partially visible. 


\subsection{Deterministic and stochastic}

If one is able to know the next state of the agent from the current state and actions taken till now, the environment is deterministic; otherwise, the environment is called stochastic.

\subsection{Periodical or non-periodical}

If the environment is independent of other periods in each period, it is periodical, or else it is non-periodical.

\subsection{Static and dynamic}

If the environment changes in the course of making decision, it is dynamic, or else it is static. However, if the environment remains stable but time reduces actor's efficiency, it is called semi-dynamic.

\subsection{Discontinuous and continuous}

If observations and actions are defined in discrete fashion, the environment is continuous, e.g. chess. But an equation optimizer actor works in the continuous environment.

\section{E-learning}

E-learning entails three educational fields namely e-management, e-services, and elearning. E-management system is based on an effective management patters, for which we can refer to POSDCARE pattern.

The model constitutes planning which means planning via the Internet, organizing which means virtual organizations, staffing which means recruitment via the internet, directing which means controlling and guiding via e-mail, fax, phone, coordinating which means networking of collaborators, allocation of resources which means electronic banking and money transfer, reporting which means sending reports via e-mail, finally evaluation which means supervision via the internet.

In e-service system, offering and receiving services are undertaken through electronic devices. The first step to the development of e-learning is content production.

\section{Features of e-learning}

Learning courses are interactive, meaning that courses are available by instructors who are in different locations for all age groups everywhere and anytime, and are presented in the internet, in that a variety of learning methods are used. Virtual classroom, simulation, collaboration, assembly, and even physical classroom include all educational stages namely enrollment, education, evaluation, and presentation of certification. Management, enrollment, tuition, and supervision over the network are dynamic, because they tap into 
the latest information resources and run online and live in time. Learners, instructors, and experts are come together in this way. Give the interests, abilities, and pace of each person, it can be used. It makes use of all information resources and bases. This kind of quick but low-cost learning increases equal learning opportunities.

\section{Products of e-learning}

Learning products produced by various institutions and usable in e-learning courses are categorized into four classes; learning courses that end up with a degree including longterm learning courses, short-term courses, reference network websites, and e-learning software programs.

\section{Main methods of e-learning}

Main practices of e-learning include personal learning, collective learning, and virtual classrooms. As for personal learning, a major of interest is chosen by person and searched and reviewed via the internet, and the person asked expert instructors some questions of his own indirectly. Regarding collective learning, online conversation (chat) has a crucial role. Using this practice, learners can attend the classroom simultaneously and from a distance and discuss a course subject. One person takes on the role of director and leader in this regard and raises some points and questions for the discussion. In virtual classrooms, which is the best and efficient technique of e-learning, education is based on video conference technology; in this method, instructor and learner can see one another online and talk and discuss.

\section{Components and architecture of e-learning system}

Learning Management System (LMS) and Learning Content Management System (LCMS)

\subsection{Learning Management System (LMS)}

Learning management system is a software that takes over the learning management of an organization. The system is a reaching point to a set of learning resources; this tool makes LMS automatic and makes available new features.

\subsubsection{Features and characteristics of LMS}

Individual guidance in the whole course which includes virtual classroom, enrollment management and data storage, simultaneous management of various components involved in learning, learning resource management and their presentations, access level management and safety problems, saving progress, performance of students, interaction management and management system of various learning models. 


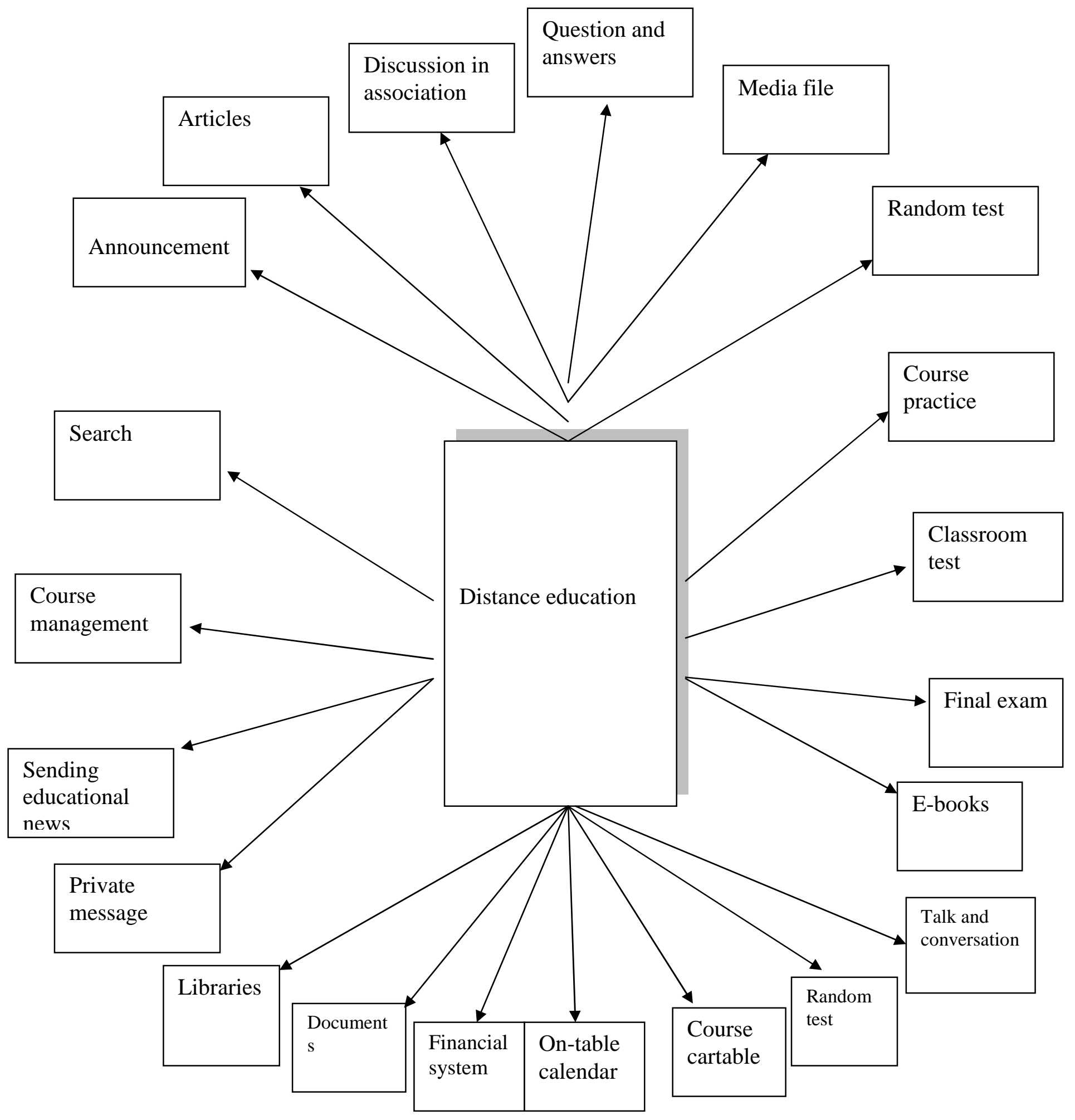

Figure 1: A simple example of LMS components 


\subsection{Learning Content Management System (LCMS)}

It is a knowledge management system that provides the opportunity for collection of information in various forms and formats, their storage in storehouse, and sharing, reusing, modularity management, their packing in the way that it is possible to present them as a learning course. The system takes over the management of learning things available in learning storehouses.

\section{Intelligent agents in e-learning}

Many e-learning environments fail to offer good support compared with traditional learning environments. Smartization of environments can fix this. Smart environments can adjust changes with regard to user's personal needs. Smartization is achieved by using intelligent software agent technology. Intelligent software agents are systems that make decisions autonomously and without user interaction. Intelligent agents would help user communicate with a computer program more efficiently.

\section{Results}

In this research, a wide set of e-learning agent were elaborated, that can contribute to elearning. E-learning agents can function as a support for mentors and instructors so that they can continually see available contents and opt for the best learning contents. Up-todate extraction of learning contents, easy, comfortable and fast contact between teacher and student, and supervision over teacher's and student's performance during learning process are considered advantages provided by a system based on intelligent agents of elearning. Providing essential groundworks including internet communicative lines with high speed and fair price, presenting good hardware and software services, supporting founders of virtual and electronic learning, networks, and transferring knowledge about elearning and promoting its culture are influential factors in the level of using intelligent learning systems and the success of the system.

\section{References}

[1] Lindberg, R. Seo, J. and Teemu H. Laine (2016), "Enhancing Physical Education with Exergames and Wearable Technology", IEEE Transactions on Learning Technologies, pp 328 - 341.

[2] Ruano, I. Gámez, J. Dormido, S. and Gómez, J. (2016), “A Methodology to Obtain Learning Effective Laboratories with Learning Management System Integration", IEEE Transactions on Learning Technologies, pp 391 - 399.

[3] Ibáñez, M. Di-Serio, A. Delgado-Kloos, C. (2014), "Gamification for Engaging Computer Science Students in Learning Activities: A Case Study”, IEEE Transactions on Learning Technologies, pp 291 - 301. 
[4] Mahdion, R. Ghahramani, M. Farasatkhah, M. Hosseinishavoon, A. (2011), "Dimensions and components of e-learning quality assurance in higher education and presentation of a conceptual model for it", The 6th National Conference and 3rd International Conference on E-learning.

[5] Jamparazami, M. Hosseinzadeh, M. (2011), "Presentation of an approach to evaluation of e-learning system performance; a synthetic approach to fuzzy hierarchical analysis and vital factors of success", 6th National Conference and 3rd International Conference on E-learning.

[6] A.K.M. Najmul Islam, (2016)", E-learning system use and its outcomes: Moderating role of perceived compatibility", Telematics and Informatics Journal, pp 48 - 55.

[7] Dominici, G. Palumbo, F. (2013), "How to build an e-learning product: Factors for student/customer satisfaction", Business Horizons Journal, pp 87 - 96.

[8] Stoffregen, J. Pawlowski, J. M. Pirkkalainen, H. (2015), "A Barrier Framework for open E-Learning in public administrations”, Computers in Human Behavior Journal, pp $674-684$.

[9] Pandey, N. Tyagi, R. K. Sahu, S. and Dwivedi, A. (2013), "Learning algorithms for intelligent agents based e-learning system", Advance Computing Conference (IACC), 2013 IEEE 3rd International.

[10] W. Li and X. Li, (2009), "Design of a Personalized Learning System Based on Intelligent Agent for E-learning", In Ninth International Conference on Hybrid Intelligent Systems, pp. 187-190.

[11] Pandey, N. Sahu, S. and Ahmed, P. (2012), "Automated requirements gathering using intelligent agents for e-learning system", International Journal of Soft Computing and Engineering (IJSCE), pp 493-496.

[12] Shafia, M.A. Ahekri, A. (2009), "Presentation of a model of learning efficiency measurement and increase in virtual (electronic) learning systems", The 4th National Conference and 1st International Conference on E-learning.

[13] Atici. B, (2011), "Effect on Learners' Achievement of Using Language in Online Learning Environments, Information", pp 235-249.

[14] Kordtodashki, L. (2009), "Presentation of service-focused architecture based on web for construction of distributed learning management system compatible with SCORM", The 4th National Conference and 1st International Conference on Elearning.

[15] Mojtahedzadeh, R. Mohammadi, A. Borjalilou, S. (2011). "Comparison of education self-regulation, objective orientation and education progress among students of elearning and attendance systems", The 6th National Conference and 3rd International Conference on E-learning.

[16] Devedzic. V. (2003), "Key issues in next-generation Web-based education", IEEE Transactions on Systems, Man, and Cybernetics, pp 339-349.

[17] Allison, C. Cerri, S.A. Ritrivato, P. Gaeta, A. and Gaeta, M. (2005), "Services, semantics and standards: elements of a learning grid infrastructure", Applied Artificial Intelligence, Vol. 19, pp 861-79. 
Bulletin de la Société Royale des Sciences de Liège, Vol. 86, special edition, 2017, p. 398 - 405

[18] Gladun, A. and Rogushin, J. (2007), "An Ontology-Based Approach to Student Skills In Multiagent e-Learning Systems", Int. J. Info. Techn. and Knowledge, pp 219-225.

[19] Zhang, L. Zhuang, Y. Yuan, Z. and Zhan, G. (2007), "Auto Diagnosing: An Intelligent Assessment System Based on Bayesian Networks", Proceeding of 37th ASEE/IEEE Frontiers in Education Conference.

[20] Rady, T.E.and Shavlik, J. "A system for building intelligent agents that learn to retrieve and extract information", International Journal on User Modeling and UserAdapted Interaction, pp 35-88 2002.

[21] Nedev, D. and Nedeva, V. (2006), "Aspects of multi-agent systems application in elearning", Proceedings of International Scientific Conference Computer Science, pp 1022-1027.

[22] Liu, Z. Wang, Z. and Fang, Z. (2006), "An agent-based e-learning assessing and instructing system", Proceedings of the 10th International Conference on Computer Supported Cooperative Work in Design IEEE, pp 1-6. 